\title{
A 4-year-old boy presenting with chronic constipation and ribbon like stool
}

\author{
Md. Benzamin, Kaniz Fathema, Rubaiyat Alam, Bishnu Pada Dey and Mohammad Tosaddeque \\ Hossain Siddiqui
}

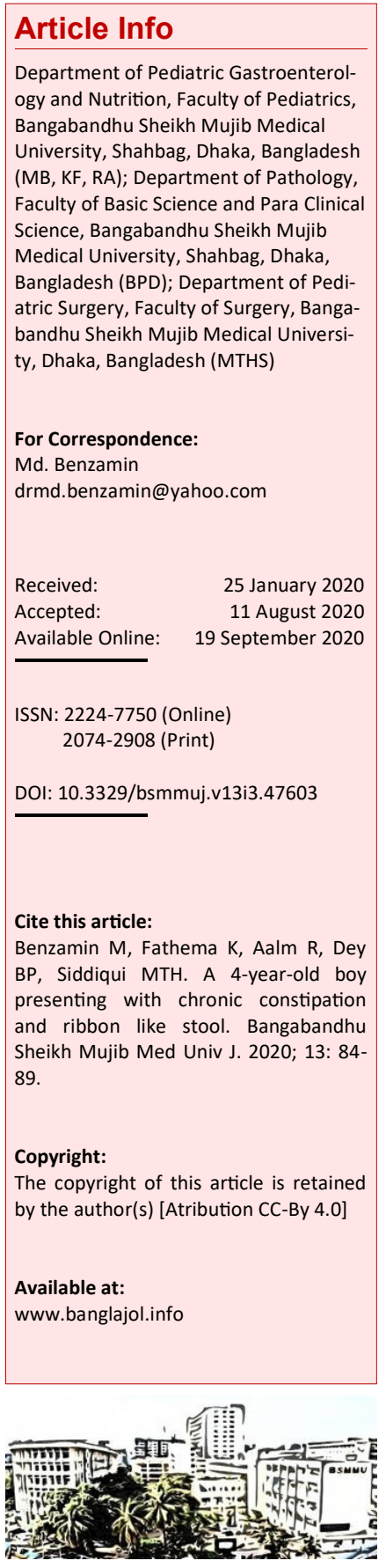

\section{Presentation of Case}

Dr. Md. Benzamin (Resident): A 4-year-old boy presenting with constipation for 1 month of his age. He used to defecate 3-4 days interval with rectal stimulation. The stool was semisolid, ribbon-like, and not associated with abdominal or perianal pain. He had a history of delayed passage of meconium. There was no history of the delayed developmental milestones. He received several medications including lactulose, magnesium hydroxide but there was a poor response.

On examination, he was mildly pale, with no facial dysmorphism, anthropometrically well thrived. The back and spine were normal. There was no thyroid swelling. The skin was normal. The tone and jerk of lower limbs were normal. The abdomen was normal in shape. The digital rectal examination revealed increase anal tone, empty rectum and on finger withdrawal, gas and liquid stool came out.

On investigations, mild anemia (hemoglobin $12.1 \mathrm{mg} / \mathrm{dL})$, leucocytosis $\left(17,500 / \mathrm{mm}^{3}\right)$, and thrombocytosis $\left(500,000 / \mathrm{mm}^{3}\right)$ were found. The thyroid profiles and serum electrolytes were normal. The plain X-ray abdomen showed fecal impaction with gas distended bowel loops (Figure 1). So, we provisionally diagnosed this case.

\section{Provisional Diagnosis \\ Hirschsprung's disease}

\section{Differential Diagnosis}

Dr. Kaniz Fathema (Resident): As the child was well thriving with no facial dysmorphism, and no features suggestive of hypothyroidism, spinal cord defect or neurological disease, we differentially thought about functional constipation.

\section{Functional constipation}

Dr. Fathema: Constipation is a common chronic disorder of the pediatric age group, affecting $1 \%$ to $30 \%$ of children worldwide. 1 In Asia, the prevalence is between $0.5 \%$ to $29.6 \%$.2 Constipation accounts for $3 \%$ of all primary pediatric care visits and $10-25 \%$ of pediatric gastroenterologist visit. 3

North American Society for Pediatric Gastroenterology, Hepatology and Nutrition defines constipation as a delay or difficulty in defecation, present for 2 or more weeks and sufficient to cause significant distress to the patient.. Functional constipation is defined as constipation without objective evidence of a pathologic condition. $\frac{5}{}$ As per ROME IV criteria for $\geq 4$ years children, the functional constipation is defined as the presence of at least two of the followings present at least once per week for at least one month: a) Two or fewer defecations in the toilet per week in a child of a developmental age of at least 4 years; b) At least one episode of fecal incontinence per week; c) History of retentive posturing or excessive volitional stool retention; d) History of painful or hard bowel movements; e) Presence of a large fecal mass in the rectum; and f) History of large-diameter stools that may obstruct the toilet.

These symptoms cannot be fully explained by another medical condition and symptoms are insufficient to fulfill the diagnostic criteria of irritable bowel syndrome. 6 Functional constipation usually initiates with a painful bowel movement which leads to voluntary withholding of stools to avoid painful defecation. These events lead to large, hard stool, and passage of such stool causes further pain and the child becomes frightens, then avoids defecation by all means. Thus, a vicious cycle develops $\underline{7,8}$ Presence of following "red flag" exclude the diagnosis of functional constipation, like the passage of meconium $>48$ hours in a term newborn, constipation starting in the first month of life, family history of Hirschsprung's disease, ribbon-like stool, blood in stools in absence of anal fissure, failure to thrive, bilious vomiting, severe abdominal distention, abnormal thyroid gland, abnormal 


\begin{tabular}{|lrr|}
\hline \multicolumn{2}{|c|}{ Table I } \\
\hline \multicolumn{2}{|c|}{ Laboratory investigations } \\
\hline Investigations & Results & \multicolumn{1}{c|}{ Reference } \\
\hline Hemoglobin $(\mathrm{g} / \mathrm{dL})$ & 12.1 & $13-17$ \\
White blood cells $\left(/ \mathrm{mm}^{3}\right)$ & 17,500 & $4,500-5,500$ \\
Platelet $\left(/ \mathrm{mm}^{3}\right)$ & 500,000 & $150,000-450,000$ \\
Serum free thyroxine $(\mathrm{ng} / \mathrm{dL})$ & 5.4 & $4.5-12.5$ \\
Serum thyroid stimulating hormone & 2.3 & $0.7-5.7$ \\
(mIU/mL) & & $136-145$ \\
Serum electrolytes $(\mathrm{mmol} / \mathrm{L})$ & $\mathrm{Na}+137$ & $3.5-4.5$ \\
& $\mathrm{~K}+4.5$ & $98-107$ \\
\hline
\end{tabular}

position of anus, absent anal or cremasteric reflex, decrease lower limb strength/tone/reflex, sacral dimple, tufts of hair on spine, gluteal cleft deviation, anal scar, etc. 9

Dr. Benzamin: As the patient having red flag signs that are delayed passage of meconium, constipation straining in the first month of life, and have a poor response to treatment of functional constipation, we have a strong suspicion about Hirschsprung's disease. So, we did barium enema which showed a dilated colon and a significant amount of contrast retained in post evacuation and 24 hours film (Figure 1). So, we went for a rectal biopsy.

Dr. Hazera Akther (Resident): The rectal biopsy should be done for confirmation of Hirschsprung's disease, if initial tests suggest the diagnosis of Hirschsprung's disease, or have a high index of suspicion. The gold standard for the diagnosis of Hirschsprung's disease is a full-thickness biopsy. Several samples of the rectal mucosa should be obtained 1 to $3 \mathrm{~cm}$ above the dentate line and should include the submucosa. The rectal suction biopsy collects only the mucosa. The diagnostic pathological findings are the absence of submucosal and myenteric ganglion cells with hypertrophied nerve trunk. The sensitivity and specificity of rectal suction biopsy are 96.8 and 99.4 respectively. If no hypertrophic nerve trunks are found, then a fullthickness biopsy maybe indicated.10-12

Dr. Bishnu Pada Dey (Assistant Professor): Histopathology report of the rectal biopsy showed disorganized, non-myelinated, nerve bundles present in myenteric plexus and Meissner's plexus. No ganglionic cell was seen in the myenteric plexus and Meissner's plexus (Figure 2). These features are suggestive of Hirschsprung's disease.

The histopathology of Hirschsprung's disease includes the complete absence of ganglia in both Meissner submucosal plexus and Auerbach myenteric plexus. Associated nerve hypertrophy is a helpful clue but is not diagnostic. Ganglia in the newborn are smaller than in the older child and nucleoli and Nissl substance may be absent. Ganglia near the junction of the ganglionic and aganglionic segment may be decreased in number or be small with abnormal staining patterns. $\underline{13}$

\section{Dr. Benzamin's Diagnosis}

\section{Hirschsprung's disease}

Prof. Mohammad Tosaddeque Hossain Siddiqui: Singlestage transanal pull-through operation was done with resection of aganglionic segment and anastomosis of normal ganglionated bowel to the rectum without injuring the anal sphincter and there were no post-operative events. The tissue from the proximal and distal length was examined for histopathological confirmation.
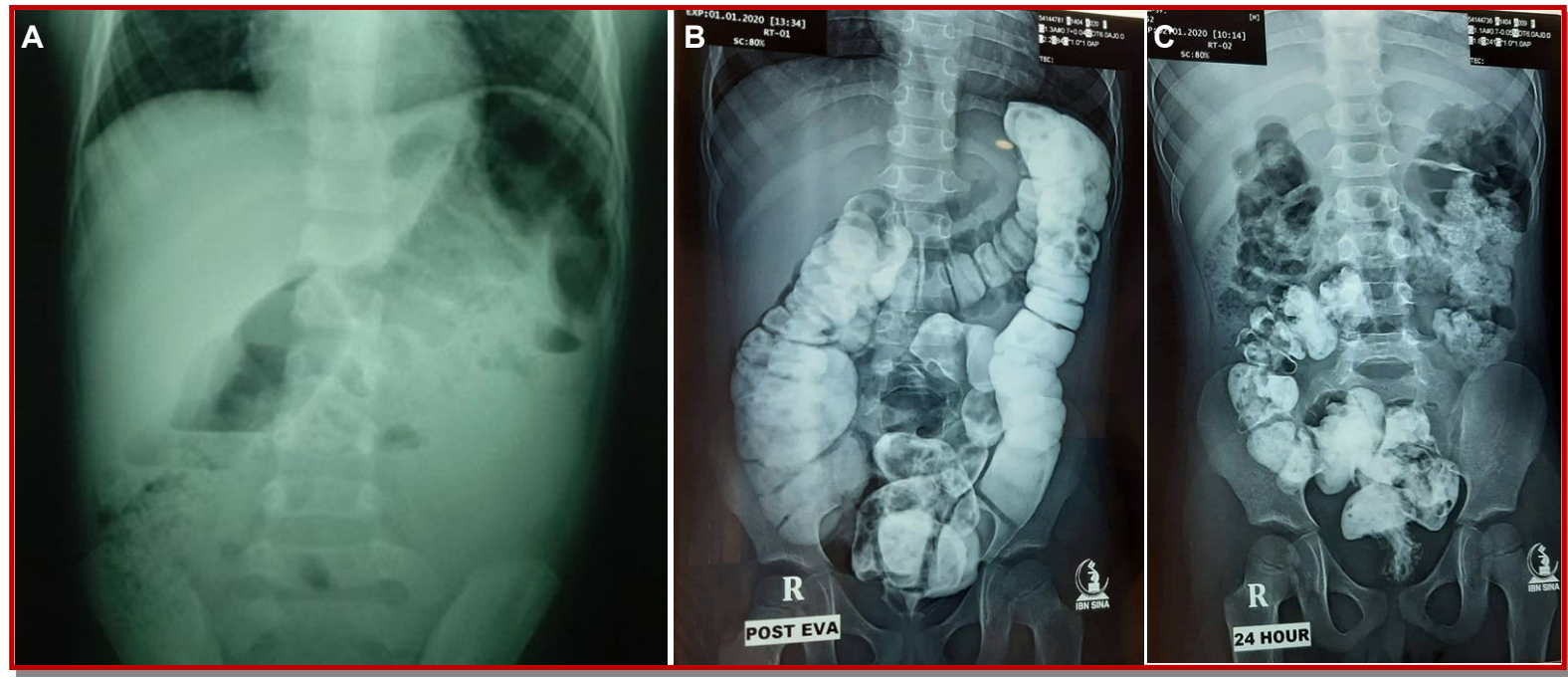

Figure 1: Plain X-ray abdomen shows fecal impaction with gas distended bowel loops (A), Barium enema shows dilated large gut (B), and Significant amount of contrast retained in post evacuation and 24 hours film (C) 


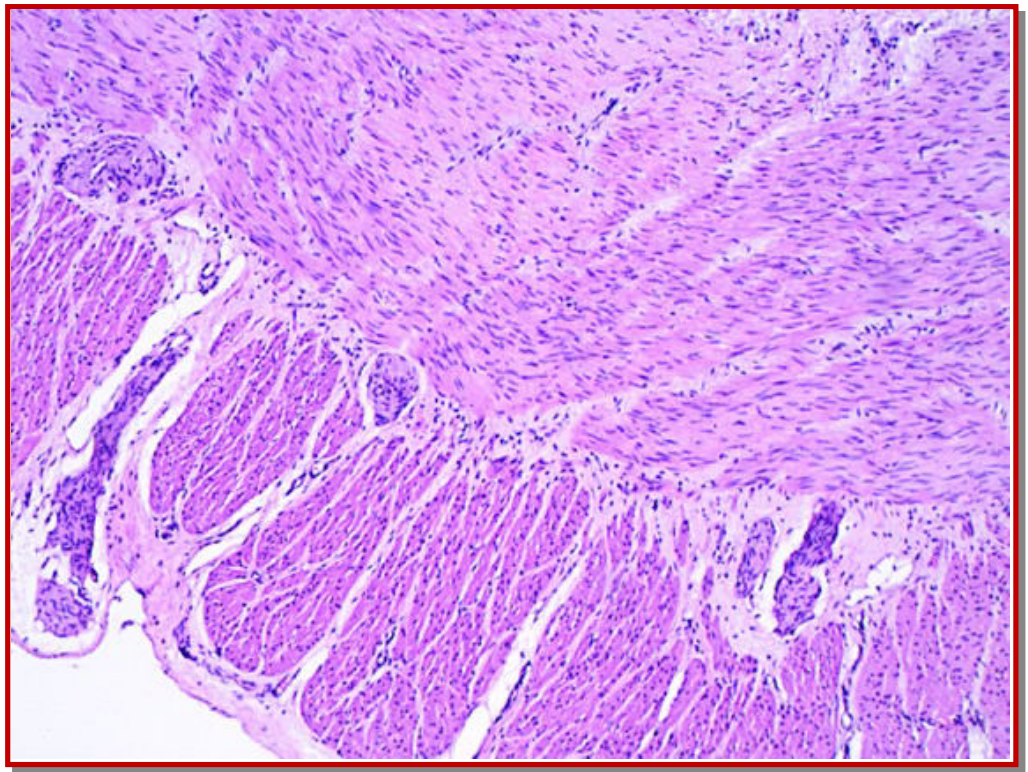

Figure 2: Histopatholgy of Hirschsprung's disease

\section{Discussion}

Dr. Rubaiyat Alam (Assistant Professor): Hirschsprung's disease, or congenital intestinal aganglionosis, is a birth defect. $\underline{14}$ It is characterized by the complete absence of neuronal ganglion cells in the myenteric Auerbach's plexus, the deep submucosal Henle's plexus, and the submucosal Meissner's plexus from a portion of the intestinal tract. The aganglionic segment includes the distal rectum and a variable length of contiguous proximal intestine. $15-$ 17 The incidence is usually reported as 1 in 5,000 newborns and 3 times more common among the Asian-Americans. 18,19 More common in boys than girls (male-to-female ratio 4:1). The most common cause is the lower intestinal obstruction in the neonate. Approximately $50 \%$ of Hirschsprung's disease cases are diagnosed in neonates. $\underline{14,15,20,21}$ The cause of Hirschsprung's disease is multifactorial, and the disease can be familial or develops spontaneously. 17 The cause of the disease is the arrest of migration and differentiation of enteric neural crest-derived cells. 22 Hirschsprung's disease usually present in infancy, although some patients present later in life.

Symptoms range from neonatal intestinal obstruction to chronic progressive constipation in older children. 23,24 Symptoms of Hirschsprung's disease in the neonate are a) failure to pass meconium in the first 24 hours of life; b) abdominal distension that is relieved by rectal stimulation or enemas; c) vomiting and d) neonatal enterocolitis.

Symptoms of Hirschsprung's disease in the infant are a) bilious vomiting; b) enterocolitis-associated diarrhea; c) infrequent, explosive bowel movements; d) difficult bowel movements, e) jaundice, f) poor feeding, g) progressive abdominal distention.

Symptoms of Hirschsprung's disease in older children are a) absence of soiling or overflow incontinence; b) chronic progressive constipation, usually with onset in infancy; c) failure to thrive; d) fecal impaction; e) enterocolitis-associated diarrhea; e) malnutrition, f) progressive abdominal distention, and g) history of constipation with frequent rectal irrigation. $\underline{23-25}$

On examination, the abdomen may be distended, failure to thrive and associated congenital anomaly may found.26 DRE is always necessary. $\underline{27}$ Diagnosis is done by the combination of clinical features, examination findings, and investigations.

Dr. Nazmul Hassan (Resident): What is the expected finding on the digital rectal examination?

Dr. Dipannita Shaha (Resident): On inspection, there was no lesion on the perianal area. On finger insertion through the anus, there will tight anal sphincter, often with the absence of stool in the rectal vault and on withdrawal of the finger explosive discharge of stool and gas. $\underline{27}$

Dr. Saidul Islam (Resident): What are the type of Hirschsprung's disease?

Dr. Benzamin: Classification is done based on the extension of the aganglionosis as follows: a) Classic form (short segment; 70-75\% cases; limited to the rectum and sigmoid colon); b) The long segment, or subtotal colonic disease (10-15\%), generally involves the bowel up to the splenic flexure; c) Total colonic aganglionosis (3-6\%) may extend to involve a variable amount of the short bowel; d) Total intestinal aganglionosis; and e) Ultrashort-segment variant involving the distal rectum below the pelvic floor and the anus. $\underline{28,29}$ Here, the aganglionic segment is limited to the internal sphincter. Here, the child presents with the feature of functional constipation. Ganglion cells are present on the rectum, but the rectal motility is abnormal.모

Dr. Nahid-E-Subha (Resident): What are the associated anomalies and syndromes may be present?

Dr. Shaha: Associated congenital anomalies are around $21.1 \%$ among them $12 \%$ are with associated chromosomal anomalies. Congenital anomalies of the gastrointestinal tract $(8.1 \%)$, genitourinary system $(6.05 \%)$ and central nervous system $(6.8 \%)$, musculoskeletal system (5.1\%), cardiovascular system $(5.0 \%)$, craniofacial area $(3 \%)$, and skin (ectodermal dysplasia). Syndromic Hirschsprung associations include Down syndrome, dominant sensorineural deafness, Waardenburg syndrome, neurofibromatosis, neuroblastoma, pheochromocytoma, the multiple endocrine neoplasia Type II syndromes, and syndromes related to cholesterol and fat metabolism. $.17,30$ 
Dr. Parisa Marjan (Resident): What is the most common cause of mortality in Hirschsprung's disease?

Dr. Fathema: Hirschsprung's disease enterocolitis can occur preoperatively in up to $50 \%$ cases. Postoperative complications are up to $22 \%$ cases. 31 This condition causes mortality of $1-10 \%$ in the newborn Hirschsprung's disease. 32 Fecal stasis from aganglionosis leads to bacterial overgrowth in the gut, followed by inflammation of the mucosa with fever and an elevated white blood cell count. $\underline{23,24,33}$

Dr. Nazmul Ahmed (Resident): What are investigations modality for diagnosis of Hirschsprung's disease and which one is the gold standard?

Dr. Benzamin: The plain X-ray abdomen, barium enema, anorectal manometry, and rectal biopsy. The gold standard for the diagnosis of Hirschsprung's disease is full-thickness biopsy. $\underline{.11,12,30}$

Dr. Nyeema Rahman (Resident): What are the findings on plain X-ray abdomen that may give clues for suspicion of Hirschsprung's disease?

Dr. Fathema: Dilated loops of the bowel, often with the absence of stool and gas in the rectum may give clues. Air-fluid levels in the colon (if intestinal obstruction), pneumatosis intestinalis and free air in the abdomen (in enterocolitis with perforation). Lateral view may occasionally demonstrate a narrow rectum. If small bowel obstruction is prominent, a longer aganglionic segment should be consider..$\underline{30}$

Dr. Mahmudul Hassan (FCPS student): What are findings on barium enema that may give diagnosis of Hirschsprung's disease?

Dr. Benzamin: The transitional zone, which is the junction point between the normal and aganglionic bowel, most commonly in the recto-sigmoid colon. The transition zone represents the site where the narrow aganglionic bowel joins the dilated ganglionic bowel. On plain X-ray on after 24 hours of study, if the contrast remaining in the rectum, is also suggestive of the diagnosis. The recto-sigmoid index (the ratio of the diameter of the rectum to the diameter of the sigmoid colon) will be less than 1.30 , $\underline{34,35}$

Dr. Afsana Yasmin (Resident): Is anorectal manometry always necessary for the diagnosis of Hirschsprung's disease?

Dr. Shaha: Manometry is now considered to be unnecessary because the reflex also can be evaluated with a modified contrast enema.11 But it is useful especially in the older child to differentiate Hirschsprung's disease especially ultra short-segment Hirschsprung's disease from the other causes of constipation. $\underline{36}$

Dr. Kamal Hossen (Resident): When the barium enema contraindicated?

Dr. Benzamin: The contrast enemas should be avoided in patients with enterocolitis because of the risk of perforation. $\underline{24}$ The barium enema is commonly normal in the first three months of life and indefinitely in total colonic aganglionosis..$\underline{33}$

Dr. Shashi Bhusan Thakur (Resident): What are the treatment options?

Dr. Siddiqui: Surgery is usually needed. The treatment is resection of the aganglionic segment and anastomosis of normal ganglionated bowel to the rectum without injuring anal sphincter. Three definitive surgical procedures commonly performed for Hirschsprung's disease: Swenson procedure (removal of the aganglionic portion of the colon), Duhamel procedure (retro-rectal anastomosis) or Soave pro-cedure (endorectal pull-through). $.15,16,37$

Dr. Maimuna Sayeed (Resident): What are the preoperative management before surgery?

Dr. Siddiqui: Serial rectal irrigations are done to prevent enterocolitis and to reduce colonic distension. Rectal irrigation with 10 to $20 \mathrm{~mL} / \mathrm{kg}$ of warm $0.9 \%$ sodium chloride solution facilitates the passage of stool and to keep the rectum decompressed. $\underline{38}$

Dr. Ayesha Sabiha (Resident): What is the management of Hirschsprung's disease enterocolitis?

Dr. Siddiqui: Intravenous fluids, nasogastric suction, antibiotic coverage are for Gram negative organisms and anaerobes. The rectal irrigation 2-4 times per day should be done until decompression. After decompression, colostomy placed for several months until the child recovers and waiting for definitive surgery $\cdot \underline{39}$

Dr. Sharmin Akther (Resident): What are the complication that may encounter in Hirschsprung's disease?

Dr. Siddiqui: If untreated, there may be intestinal obstruction, enterocolitis, or even death.

Early post-operative complications are anastomotic insufficiency, rectal stenosis, prolonged ileus, intestinal adhesive obstruction, intrapelvic abscesses, presacral abscesses, metabolic derangements. Late post-operative complications are enterocolitis, stricture, resistant constipation, fecal incontinence, enuresis, incontinence of urine, dysuria, impotence. 30,39 , $\underline{40}$

Dr. Sharmista Ghosal (Resident): What is the prognosis?

Dr. Fathema: Hirschsprung's disease is a surgically correctable condition. If the patient appropriately treated, growth and development are mostly within the normal population parameters and intellectual function approximates normal. $\underline{11}$ This patient's post- 
operative period was uneventful and he was passing stool normally.

\section{Follow-up}

The patient was doing well with regular bowel movement on 2 weeks after follow-up.

\section{Final Diagnosis}

Hirschsprung's disease

\section{Conflict of Interest}

The authors declare no conflict of interest.

\section{References}

1. Van den Berg MM, Benninga MA, Di Lorenzo C. Epidemiology of childhood constipation: A systematic review. Am J Gastroenterol. 2006; 101: 2401 09.

2. Mugie SM, Benninga MA, Di Lorenzo C. Epidemiology of constipation in children and adults: A systematic review. Best Pract Res Clin Gastroenterol. 2011; 25: 3-18.

3. Zhang SC, Wang WL, Qu RB, et al. Epidemiologic survey on the prevalence and distribution of childhood functional constipation in the northern areas of China: A population-based study. Zhonghua Liu Xing Bing XueZaZhi. 2010; 31: 751-54.

4. Walter HA, Hovenkamp A, Rajindrajith S, Devanarayana NM, Rajapakshe NN, Benninga MA. OP12 prevalence of functional constipation in infants and toddlers in Sri Lanka. JPGN. 2015; 61: 541.

5. Bhatia V, Deswal S, Seth S, Kapoor A, Sibal A, Gopalan S. Prevalence of functional gastrointestinal disorders among adolescents in Delhi based on Rome III criteria: A school-based survey. Indian J Gastroenterol. 2016; 35: 294-98.

6. Amendola S, De-Angelis P, Dall'Oglio L, Di Abriola GF, Di Lorenzo M. Combined approach to functional constipation in children. J Pediatr Surg. 2003; 38: 819-23.

7. Borowitz SM, Cox DJ, Tam A, Ritterband LM, Sutphan JL, Penberthy JK. Precipitant of constipation during early childhood. J Am Board Fam Pract. 2003; 16: 213-18.

8. Tabbers MM, Di Lorenzo C, Berger MY, Faure C, Langendam MW, Nurko $S$, et al. Evaluation and treatmentof functional constipation in infants and children: Evidence-based recommendations from ESPGHAN and NASPGHAN. J Pediatr Gastroenterol Nutr. 2014; 58: 258-74.
9. Hyams JS, Lorenzo CD, Saps M, Shulman RJ, Staiano A, Tilburg MV. Childhood functional gastrointestinal disorders: child/Adolescent. Gastroenterology 2016; 150: 1456-68.

10. Khan AR, Vujanic GM, Huddart S. The constipated child: How likely is Hirschsprung's disease? Pediatr Surg Int. 2003; 19: 439-42.

11. De Lorijn F, Kremer LC, Reitsma JB, Benninga MA. Diagnostic tests in Hirschsprung disease: A systematic review. J Pediatr Gastroenterol Nutr. 2006; 42: 496-505.

12. Friedmacher F, Puri P. Rectal suction biopsy for the diagnosis of Hirschsprung's disease: A systematic review of diagnostic accuracy and complications. Pediatr Surg Int. 2015; 31: 821-30.

13. Turner JR. The gastrointestinal tract: Hirschsprung Disease. In: Robins and Cortan Pathologic basis of disease. Kumer V, Abbas AK, Aster JC (eds). 9th ed. Philadelphia, Elsevier Inc, 2015, pp 782-85.

14. Amiel J, Sproat-Emison E, Garcia-Barcelo $M$ Lantieri F, Burzynski G, Borrego S, et al Hirschsprung disease, associated syndromes and genetics: A review. J Med Genet. 2008; 45: 1-14.

15. Boley SJ, Lafer DJ, Kleinhaus S, Cohn BD, Mestel AL, Kottmeier PK. Endorectal pull-through procedure for Hirschsprung's disease with and without primary anastomosis. J Pediatr Surg. 1968; 3: 258.

16. Georgeson KE, Cohen RD, Hebra A, Jona JZ, Powell DM, Rothenberg SS, et al. Primary laparoscopic-assisted endorectal colon pull-through for Hirschsprung's disease: A new gold standard. Ann Surg. 1999; 229: 678-82.

17. Parisi MA, Kapur RP. Genetics of Hirschsprung disease. Curr Opin Pediatr. 2000; 12: 610-17.

18. Best KE, Addor MC, Arriola L, et al. Hirschsprung's disease prevalence in Europe: A register based study. Birth Defects Res A Clin Mol Teratol. 2014; 100: 695-702.

19. Russell MB, Russell CA, Niebuhr E. An epidemiological study of Hirschsprung's disease and additional anomalies. Acta Paediatr. 1994; 83: 68-71.

20. Lau ST, Caty MG. Hindgut abnormalities. Surg Clin North Am. 2006; 86: 301-16.

21. Marquez TT, Acton RD, Hess DJ, Duval S, Saltzman DA. Comprehensive review of procedures for total colonic aganglionosis. J Pediatr Surg. 2009; 44: 257-65.

22. Mungnirandr A. Hirschsprung's disease: Review article. Siriraj Med J. 2017; 69: 223-27.

23. Puri P, Montedonico S. In: Hirschsprung's disease and allied disorders. Holschneider AM, Puri P (eds). 2nd ed. Amsterdam, Harwood Academic Publishers, 2000, pp 107-41.

24. Coran AG, Teitelbaum DH. Recent advances in the management of Hirschsprung's disease. Am J Surg. 
2000; 180: 382-87.

25. Torfs CP. An epidemiological study of Hirschsprung disease in a multiracial California population. The Third International Meeting: Hirschsprung disease and related neurocristopathies. France, Evian, 1998.

26. Parc R, Berrod JL, Tussiot J, Loygue J. Megacolon in adults: Apropos of 76 cases. Ann Gastroenterol Hepatol (Paris). 1984; 20: 133-41.

27. Green HL, Rizzolo D, Austin M. Surgical management for Hirschsprung disease: A review for primary care providers. JAAPA. 2016; 29; 24-29.

28. Hall NJ. Congenital problems of the gastrointestinal tract. In: Textbook of Pediatric gastroenterology, hepatology and nutrition. Guandalini S, Dhawan A, Branski D (eds). Switzerland, Springer International Publishing, 2016, pp 23-34.

29. Wyllie R. Motility disorders and Hirschsprung disease. In: Nelson textbook of Pediatrics. Kliegman R, Stanton BF, St. Geme JW, et al., (eds). $1^{\text {th }}$ ed. Philadelphia, Elsevier-Saunders, 2011, pp 1283-87.

30. SW Moore. Hirschsprung disease: Current perspectives. Open Access Sur. 2016: 9: 39-50.

31. Vieten D, Spicer R. Enterocolitis complicating Hirschsprung's disease. Semin Pediatr Surg. 2004; 13: 263-72.

32. Gosain A. Established and emerging concepts in Hirschsprung's-associated enterocolitis. Pediatr Surg Int. 2016; 32: 313-20.

33. Kessmann J. Hirschsprung's disease: Diagnosis and management. JAAPA. 2006; 74: 8.

34. Alehossein M, Roohi A, Pourgholami M, Mollaeian M, Salamati P. Diagnostic accuracy of radiologic scoring system for evaluation of suspicious Hirschsprung disease in children. Iran J Radiol. 2015; 12: e12451.

35. Pochaczevsky R, Leonidas JC. The recto-sigmoid index: A measurement for the early diagnosis of Hirschsprung's disease. Am J Roentgenol Radium Ther Nucl Med. 1975; 123: 770-77.

36. Vult von Steyern K, Wingren P, Wiklund M, et al. Visualisation of the rectoanal inhibitory reflex with a modified contrast enema. Pediatric radiology. 2013; 43: 950-57.

37. Zhang SC, Bai YZ, Wang W, Wang WL. Long-term outcome, colonic motility, and sphincter performance after Swenson's procedure for Hirschsprung's disease: A single-center 2-decade experience with 346 cases. Am J Surg. 2007; 194: 40-47.

38. Frykman PK, Short SS. Hirschsprung-associated enterocolitis: Prevention and therapy. Semin Pediatr Surg. 2012; 21: 328-35.

39. Langer JC, Minkes RK, Mazziotti MV, Skinner MA, Winthrop AL. Transanal one-stage Soave procedure for infants with Hirschsprung's disease. J Pediatr Surg. 1999; 34: 148-51.

40. Langer JC. Hirschsprung disease. Curr Opin Pediatr. 2013; 25: 368-74.

41. Ieiri S, Nakatsuji T, Akiyoshi J, et al. Long-term outcomes and the quality of life of Hirschsprung disease in adolescents who have reached 18 years or older: A 47-year single-institute experience. J Pediatr Surg. 2010; 45: 2398-402. 